\title{
Geriatrics Fact Sheet in Korea 2021
}

\author{
Ji Yeon Baek, Eunju Lee, Hee-Won Jung, Il-Young Jang \\ Division of Geriatrics, Department of Internal Medicine, Asan Medical Center, University of Ulsan College of Medicine, Seoul, Korea
}

\author{
Corresponding Author: \\ Hee-Won Jung, $\mathrm{MD}, \mathrm{PhD}$ \\ Division of Geriatrics, Department of \\ Internal Medicine, Asan Medical \\ Center, University of Ulsan College of \\ Medicine, 88 Olympic-ro 43-gil, \\ Songpa-gu, Seoul 05505, Korea \\ E-mail: dr.ecsta@gmail.com \\ ORCID:
}

https://orcid.org/0000-0002-2583-3354

\section{Il-Young Jang, MD}

Division of Geriatrics, Department of Internal Medicine, Asan Medical

Center, University of Ulsan College of

Medicine, 88 Olympic-ro 43-gil,

Songpa-gu, Seoul 05505, Korea

E-mail: onezero2@gmail.com

ORCID:

https://orcid.org/0000-0003-3617-3301

Received: June 15, 2021

Revised: June 24, 2021

Accepted: June 25, 2021
South Korea became an aged society in 2017 and is predicted to become a super-aged society by 2025. Therefore, knowing the trends among older adults and identifying the geriatric burden are crucial for both healthcare professionals and policymakers. We previously summarized the general health and socioeconomic profiles of Korean older adults from the 2017 National Survey of Living Conditions and Welfare Needs of Older Koreans. In this update, we briefly summarized the results of the 2020 National Survey of Living Conditions and Welfare Needs of Older Koreans by categorizing them according to their general aging profile, socioeconomic status, lifestyle, and health status. In addition, we reviewed recent updates in the field of frailty and sarcopenia from population-based community cohorts in Korea. We hope this study will serve as a current reference for nationwide statistical data on common clinical and social parameters used in geriatrics and gerontology.

Key Words: Aged, Frail elderly, Health services for the aged, Residence characteristics

\section{INTRODUCTION}

While the global population is aging, South Korea is one of the most rapidly aging societies worldwide. It took 17 years for Korea to transition to an aged society from an aging society, defined as proportions of the population aged 65 years or older of $\geq 14.0 \%$ and $7.0 \%$, respectively, while Japan took 24 years for the same transition. ${ }^{1)}$ More strikingly, Korea is expected to become a super-aged society, defined as a proportion of the population aged 65 years or older of $\geq 20.0 \%$, in 2025 . This prominent trend of population aging in Korea has been, to some degree, attributed to rapid economic development that accompanies the fast-growing life expectancy at birth with the establishment of modern healthcare systems after the Korean War (1950-1953) and the lowest birth rate among developed countries. ${ }^{2,3)}$

Many potential social and economic challenges arise from the unprecedented speed of population aging in Korea. Human aging biology leads to an increased prevalence of multiple chronic conditions, frailty, and functional decline in older adults. ${ }^{4,5)}$ Therefore, a given society must prepare to serve its aging population in a multifaceted manner, from developing fiscal policies to establishing healthcare models that are specially designed for older multimorbid individuals. $\left.{ }^{6}\right)$ While many policies have been developed to tackle the aging population, the sustainability and viability of modern welfare systems and government-operated healthcare systems that were originally proposed in Western countries have not been 
tested at this extreme pace of aging in Korea.

To establish future care policies for the older population, it is necessary to understand the dynamically changing social characteristics and health status of these people. In 2019, we summarized the general health and socioeconomic profiles of Korean older adults based on an analysis of data from the 2017 National Survey of Living Conditions and Welfare Needs of Older Koreans. ${ }^{7)}$ The present brief review updated the previous study from the preliminary results of the latest National Survey of Living Conditions and Welfare Needs of Older Koreans performed in 2020 by the Ministry of Health and Welfare, Republic of Korea. ${ }^{8)}$ This survey was conducted for 9 months, from March 2020 to November 2020, and encompassed 969 nationwide investigation districts and 10,097 older adults aged over 65 years. The survey investigated the general information, family and social relationships, health and functional status, economic status, leisure and social activity, and living environment of this population. For disabilities, we used data from the 2019 Long-Term Care Status Survey, a triennial study started in 2019 to assess the population characteristics of long-term care insurance (LTCI) and related services. ${ }^{9)}$ In addition, we provided a brief updated summary of recent literature from population-based studies on age-related conditions in Korea. ${ }^{10)}$ Based on this study, we intended to provide an up-to-date reference for Korean nationwide statistical data on common clinical and social parameters used in research on geriatrics and gerontology.

\section{PROFILE OF AGING IN KOREA}

According to the Korean statistics in 2019, the population aged 65 years or older was 7,746 thousand persons, accounting for $15.5 \%$ of the total population, a $4.8 \%$ increase compared to the previous year. $^{11)}$ The overall life expectancy at birth was 86.3 years in women and 80.0 years in men. In particular, the remaining life expectancies at 60 years of age were 28.1 and 23.3 years for women and men, respectively, which were an increase of 0.6 and 0.5 years, respectively, from $2018 .^{12)}$

\section{SOCIOECONOMIC STATUS OF KOREAN OLDER ADULTS}

The private income of older adults per year has steadily increased to US\$13,939 compared to US\$10,384 (2017) and US\$8,430 (2014). More than one-third (36.9\%) of the total older adults and $55 \%$ of older adults aged $65-69$ years were currently working. The proportion of employee/self-employment income and private pension increased significantly, which subsequently increased the chance of financial independence. Most older adults (78.2\%) lived as a single household: living alone or living with a spouse with frequent (more than once weekly) contact with their children, friends, and neighbors. The level of education had also increased markedly; the uneducated group shrank to $10.6 \%$ (33\% in 2008), while the proportion of older adults with education beyond high school increased to $34.3 \%$ (17.2\% in 2008) (Table 1$){ }^{8)}$

\section{LIFESTYLES OF OLDER KOREANS}

The most important lifetime activities were hobbies and leisure (37.7\%), followed by economic (25.4\%), social (19.3\%), religious $(14.1 \%)$, volunteer $(1.7 \%)$, and learning activity (0.9\%). Smartphone users accounted for $56.4 \%$ of the population, and the ability to use smartphones was far superior in young-old adults. For instance, $92.4 \%$ of individuals aged $65-69$ years could send text mes-

Table 1. Socioeconomic status of older Koreans

\begin{tabular}{|c|c|c|}
\hline \multirow{2}{*}{ Index } & \multicolumn{2}{|c|}{ Unit (\%) } \\
\hline & 2017 & 2020 \\
\hline Annual private income (US dollar) & 10,384 & 13,939 \\
\hline \multicolumn{3}{|l|}{ Type of income } \\
\hline Employee income & 13.3 & 24.1 \\
\hline Self-employment income & 13.6 & 17.1 \\
\hline Property income & 12.2 & 11.0 \\
\hline Private transfer & 22.0 & 13.9 \\
\hline Public transfer & 36.9 & 27.5 \\
\hline Private pension & 0.8 & 6.3 \\
\hline \multicolumn{3}{|l|}{ Participation in economic activities } \\
\hline Currently working & 30.9 & 36.9 \\
\hline Previously worked & 59.3 & 49.5 \\
\hline Never worked & 9.8 & 13.6 \\
\hline \multicolumn{3}{|l|}{ Residence type } \\
\hline Living alone & 23.6 & 19.8 \\
\hline Living with spouse & 48.4 & 58.4 \\
\hline Living with children & 23.7 & 20.1 \\
\hline Other & 4.4 & 1.7 \\
\hline \multicolumn{3}{|l|}{ Social network ${ }^{\text {a) }}$} \\
\hline Children (come-and-go) & 38.0 & 16.9 \\
\hline Children (contact) & 81.0 & 63.5 \\
\hline Friends or neighbors (contact) & 64.2 & 71.0 \\
\hline Relatives (contact) & 16.8 & 20.3 \\
\hline \multicolumn{3}{|l|}{ Level of education } \\
\hline Uneducated (illiterate) & 24.3 & 10.6 \\
\hline Elementary school ( $\leq 6 \mathrm{y})$ & 34.1 & 31.7 \\
\hline Middle school ( $>6$ and $\leq 9 y)$ & 16.9 & 23.3 \\
\hline High school ( $>9$ and $\leq 12 y)$ & 17.3 & 28.4 \\
\hline Beyond college $(>12 y)$ & 7.5 & 5.9 \\
\hline
\end{tabular}

${ }^{\text {a) }}$ More than once a week. 
sages compared to $19.9 \%$ among those aged 85 years and older. Most (83.8\%) older Korean adults preferred to live in the same place, and more than half (56.5\%) of the adults also desired agingin-place even with an impaired mobility status. The level of overall satisfaction with life was $49.6 \%$. Satisfaction with health status increased considerably from $37.1 \%$ (2017) to $50.5 \%$ (2020). The satisfaction with economic status also increased from $28.8 \%$ (2017) to $37.4 \%$ (2020) (Table 2). ${ }^{8}$ However, these trends should be interpreted with some caution with possible cohort or period effects along with drastic social changes.

\section{GERIATRIC SYNDROMES AND COMMON COMORBIDITIES}

\section{Common Medical Conditions}

The average number of chronic diseases in Korean older adults was 1.9 , with $84 \%$ of the population having more than one chronic disease. In comparison, $89.5 \%$ of the older population had one or more chronic diseases, $73 \%$ had two or more, and $51 \%$ had three or more in 2017. The top five chronic diseases were hypertension

Table 2. Lifestyle of older Koreans

\begin{tabular}{|c|c|c|}
\hline \multirow{2}{*}{ Index } & \multicolumn{2}{|c|}{ Unit (\%) } \\
\hline & 2017 & 2020 \\
\hline Most important activity in current life & NA & - \\
\hline Hobby and leisure activity & - & 37.7 \\
\hline Economic activity & - & 25.4 \\
\hline Social activity & - & 19.3 \\
\hline Religious activity & - & 14.1 \\
\hline Volunteer activity & - & 1.7 \\
\hline Learning activity & - & 0.9 \\
\hline Smartphone user & NA & 56.4 \\
\hline \multicolumn{3}{|l|}{ Preferred residency (healthy state) } \\
\hline Living in the same place & 88.6 & 83.8 \\
\hline Moving to a better environment & 11.4 & 16.1 \\
\hline \multicolumn{3}{|l|}{ Preferred residency (dysmobility state) } \\
\hline Living in the same place & 57.6 & 56.5 \\
\hline Living with spouse/children/siblings & 10.3 & 7.2 \\
\hline Living close to children/siblings & - & 4.9 \\
\hline Older adult care facility & 31.9 & 31.3 \\
\hline \multicolumn{3}{|l|}{ Life satisfaction } \\
\hline General & NA & 49.6 \\
\hline Health status & 37.1 & 50.5 \\
\hline Economic status & 28.8 & 37.4 \\
\hline \multicolumn{3}{|l|}{ Health awareness } \\
\hline Healthy & 37.1 & 49.3 \\
\hline Neither healthy nor unhealthy & 23.3 & 30.8 \\
\hline Unhealthy & 39.7 & 19.9 \\
\hline
\end{tabular}

NA, not applicable.
(56.8\%-64.4\%), diabetes mellitus (24.2\%-29.0\%), dyslipidemia (17.1\%-38.9\%), osteoarthritis (16.5\%), and lumbar pain or sciatica $(10 \%)$. Notably, the rate of depressive symptoms steadily decreased to $13.5 \%$ compared to $30.8 \%$ in 2008 and $21.1 \%$ in 2017 (Table 3). ${ }^{8,13-15)}$

Among the recipients of LTCI, the mean number of chronic diseases was 3.4 according to the 2019 Long-Term Care Status Survey. ${ }^{9)}$ In this population, the common diseases included hypertension $(60.3 \%)$, dementia (57.2\%), diabetes (29.3\%), arthritis (27.8\%), and stroke (25.8\%). LTCI recipients took a mean of 9.8 daily medications, and $79.4 \%$ of them took five or more medications per day.

\section{Functional and Cognitive Status}

Functional disability was assessed based on activities of daily living

Table 3. Health status and common comorbidities of Korean older adults

\begin{tabular}{|c|c|c|}
\hline Index & Unit (\%) & Reference \\
\hline Number of chronic diseases & & 8) \\
\hline$\geq 1$ & 84 & \\
\hline$\geq 2$ & 54.9 & \\
\hline$\geq 3$ & 27.8 & \\
\hline \multicolumn{3}{|l|}{ Type of chronic disease (top 5) } \\
\hline Hypertension & $56.8-64.4$ & $8,13,14)$ \\
\hline $60-69 y$ & 51.5 & \\
\hline$\geq 70 y$ & 67.2 & \\
\hline Diabetes mellitus & $24.2-29.0$ & $8,13,15)$ \\
\hline $60-69 y$ & 24.2 & \\
\hline$\geq 70 y$ & 31 & \\
\hline Dyslipidemia & $17.1-38.9$ & $8,13)$ \\
\hline $60-69 y$ & 42.8 & \\
\hline$\geq 70 y$ & 35.1 & \\
\hline Osteoarthritis & 16.5 & 8) \\
\hline Lumbar pain and sciatica & 10 & 8) \\
\hline Cognitive decline & 25.3 & 8) \\
\hline Dementia & 10.3 & 16) \\
\hline $65-69 y$ & 4.2 & \\
\hline $80-74 y$ & 8.9 & \\
\hline $75-79 y$ & 22 & \\
\hline $80-84 y$ & 27 & \\
\hline$\geq 85 y$ & 35.2 & \\
\hline Depressive symptoms & 13.5 & 8) \\
\hline Male & 10.9 & \\
\hline Female & 15.5 & \\
\hline Functional status & & 8) \\
\hline IADL disability & 6.6 & \\
\hline ADL+IADL disability & 5.6 & \\
\hline
\end{tabular}

$\mathrm{ADL}$, activities of daily living; $\mathrm{IADL}$, instrumental activities of daily living. 
$(\mathrm{ADL})$ and instrumental activities of daily living (IADL). Approximately $6.6 \%$ of older adults had limitations only in IADL, while $5.6 \%$ of older adults had limitations in both ADL and IADL. The prevalence of cognitive impairment increased to $25.3 \%$ compared to $14.5 \%$ in 2017 . In addition, the prevalence of dementia was $10.33 \%$, and increased with age (Table 3$).^{8,16)}$

\section{Disabilities and Healthcare Needs}

The proportion of LTCI recipients has been increasing in the total Korean population, from $1.0 \%$ in 2016 to $1.3 \%$ in 2018, according to the 2019 Long-Term Care Status Survey. ${ }^{9)}$ Among the recipients, $83.5 \%$ of the population used at least one long-term care service among home-based and institution-based services, at a ratio of $7: 3$. Regarding eligibility levels, $4.5 \%, 11.4 \%, 32.2 \%$, $43.8 \%$, and $7.7 \%$ of recipients were classified into levels $1,2,3,4$, and 5 , respectively. $^{10)}$

Among all LTCI recipients, the mean number of clinic visits for the last quarter was 5.3 , with $11.1 \%$ of recipients visiting clinics more than 10 times in the last quarter. In addition, $26.8 \%$ of the recipients had experienced hospitalization within the last 12 months, with $12.6 \%$ of the recipients experiencing institutionalization to convalescent hospitals.

\section{Frailty Status}

The prevalence of frailty in Korean older adults ranged from $2.5 \%$ to $55.7 \%$, as defined by the Cardiovascular Health Study (CHS) frailty phenotype, frailty index, and other operational measures (Table 4). ${ }^{17-30)}$ Recent Korean studies have shown that either frailty index, phenotype model, or physical performance measures could similarly identify older individuals at risk for geriatric adverse outcomes. ${ }^{18)}$ In addition, gait speed was inversely related to the frailty index and predicted adverse health outcomes (mortality or institutionalization). ${ }^{31)}$ The Timed Up and Go test was associated with both the CHS frailty phenotype and total Short Physical Performance Battery. ${ }^{20)}$

\section{Sarcopenia}

The prevalence of sarcopenia ranges from $4 \%$ to $46.8 \%$ according to different diagnostic criteria. Recent population-based studies have investigated diagnostic tools for sarcopenia (Table 5). ${ }^{32-39)}$

Table 4. Prevalence of frailty in Korean older adults

\begin{tabular}{|c|c|c|c|c|c|c|c|}
\hline \multirow{2}{*}{ Frailty assessment } & & \multirow{2}{*}{ Prevalence (\%) } & \multirow{2}{*}{ Settings } & \multicolumn{2}{|c|}{ Regions } & \multirow{2}{*}{ Publication year } & \multirow{2}{*}{ Study } \\
\hline & & & & Urban & Rural & & \\
\hline \multirow[t]{11}{*}{ Frailty screening } & CFS & 51.0 & Hospital (inpatients) & NA & NA & 2021 & Ko et al. ${ }^{23)}$ \\
\hline & & 45.1 & Hospital (inpatients) & NA & NA & 2021 & Han et al. ${ }^{17)}$ \\
\hline & FRAIL questionnaire & 27.0 & Community & & $\bigcirc$ & 2016 & Jung et al. ${ }^{19)}$ \\
\hline & & 12.4 & Community & $\bigcirc$ & $\bigcirc$ & 2018 & Kim et al. ${ }^{22)}$ \\
\hline & & 31.2 & Hospital (inpatients) & NA & NA & 2021 & Han et al. ${ }^{17)}$ \\
\hline & KFI & 21.3 & Community & $\bigcirc$ & & 2010 & Hwang et al. ${ }^{30)}$ \\
\hline & & 9.1 & Community & $\bigcirc$ & $\bigcirc$ & 2018 & Kim et al. ${ }^{22)}$ \\
\hline & CSHA frailty definition & 20.2 & Community & $\bigcirc$ & $\bigcirc$ & 2017 & Ko et $\mathrm{al}^{24)}$ \\
\hline & $\mathrm{TUG}^{\mathrm{a})}$ & 38.4 & Community & $\bigcirc$ & $\bigcirc$ & 2020 & Lee et al. ${ }^{25)}$ \\
\hline & $\mathrm{SPPB}^{\mathrm{b})}$ & 18.2 & Community & $\bigcirc$ & $\bigcirc$ & 2020 & Jung et al. ${ }^{20)}$ \\
\hline & & 55.7 & Community & & & 2021 & Jung et al. ${ }^{18)}$ \\
\hline \multirow[t]{6}{*}{ Frailty phenotype } & $\mathrm{SOF}$ & 2.5 & Community & $\bigcirc$ & $\bigcirc$ & 2018 & Kim et al. ${ }^{22)}$ \\
\hline & CHS phenotype & 8.4 & Community & $\bigcirc$ & $\bigcirc$ & 2008 & Park et al. ${ }^{28)}$ \\
\hline & & 13.2 & Community & $\bigcirc$ & & 2014 & Jung et al. ${ }^{21)}$ \\
\hline & & 17.0 & Community & & $\bigcirc$ & 2016 & Jung et al. ${ }^{19)}$ \\
\hline & & 11.4 & Community & $\bigcirc$ & $\bigcirc$ & 2018 & Kim et al. ${ }^{22)}$ \\
\hline & & 7.7 & Community & $\bigcirc$ & $\bigcirc$ & 2020 & Lee et al. ${ }^{26)}$ \\
\hline \multirow[t]{2}{*}{ Frailty index } & KFI-PC & 17.5 & Community & $\bigcirc$ & $\bigcirc$ & 2020 & Won et al. ${ }^{29)}$ \\
\hline & Frailty index & 26.3 & Community & & $\bigcirc$ & 2021 & Jung et al. ${ }^{18)}$ \\
\hline \multirow[t]{2}{*}{ Social frailty } & Social frailty index & 20.5 & Community & & $\bigcirc$ & 2019 & Park et al. ${ }^{27)}$ \\
\hline & Social deficit level & 32.4 & Community & 0 & $\bigcirc$ & 2020 & Lee et al. ${ }^{26)}$ \\
\hline
\end{tabular}

CFS, Clinical Frailty Scale; CHS, Cardiovascular Health Study; CSHA, Canadian Study of Health and Aging; KFI, Korean Frailty Index; KFI-PC, Korean Frailty Index for Primary Care; K-FRAIL, Korean version of the Fatigue, Resistance, Ambulation, Illness, and Loss of weight scale; SOF, Study of Osteoporotic Fracture; TUG, Timed Up and Go test; NA, not available.

a) 10 seconds or longer was regarded as frail. ${ }^{\text {b) }} 9$ seconds or less was regarded as frail. 
Table 5. Prevalence of sarcopenia in Korean older adults

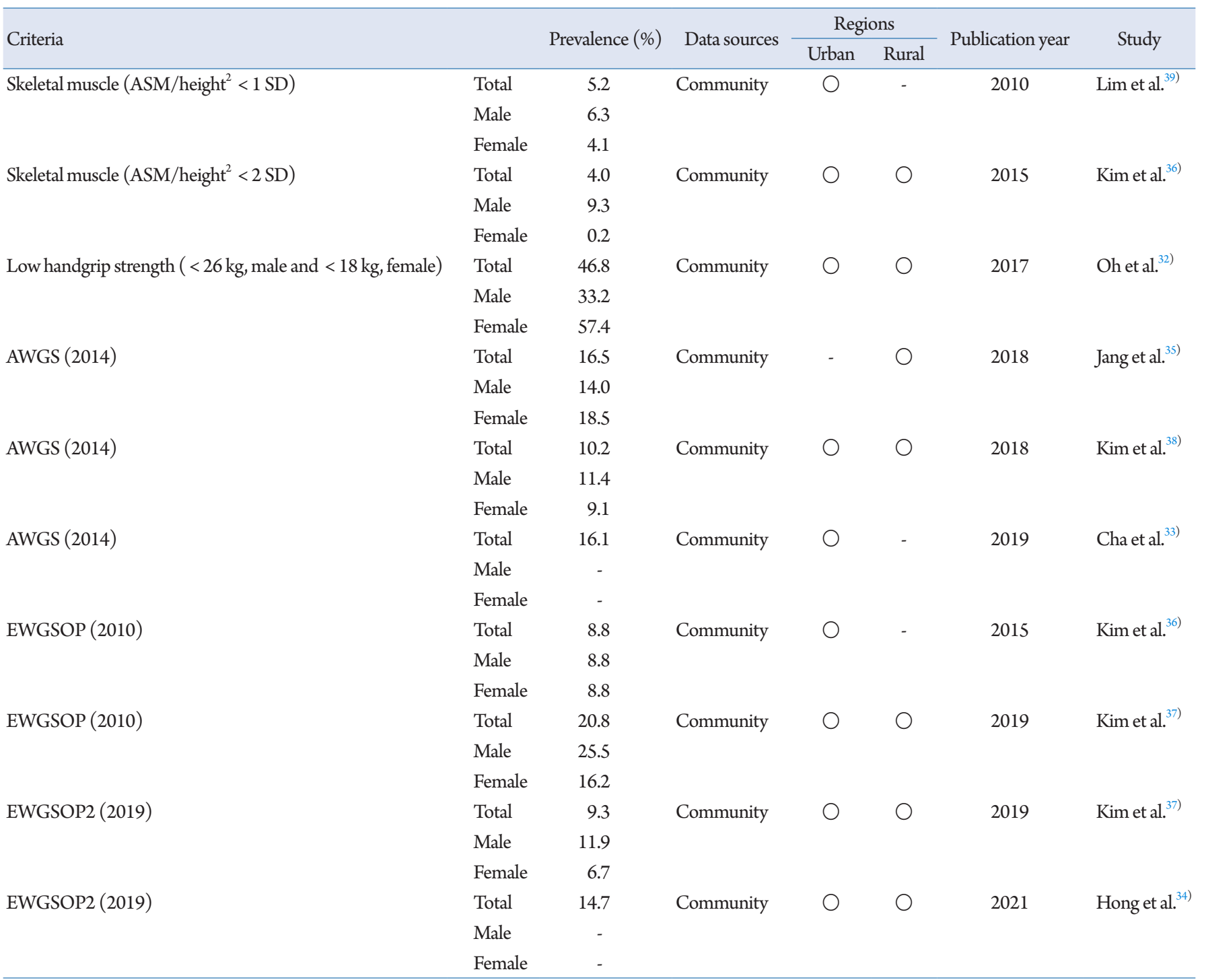

ASM, appendicular skeletal muscle; AWGS, Asian Working Group for sarcopenia; EWGSOP, European Working Group on Sarcopenia in Older People.

Calf circumference has been proposed as a surrogate marker of muscle mass because it was well correlated not only with appendicular muscle mass and skeletal muscle index but also with physical function. ${ }^{40)}$ In addition, skeletal muscle radiodensity measured using computed tomography at the third lumbar vertebra level was positively associated with jump power, which was positively correlated with sarcopenia, as defined by the European Working Group on Sarcopenia in Older People (EWGSOP2). ${ }^{34)}$ Recently, a novel sarcopenia phenotype score (SPS), which is the sum of each abnormal sarcopenic marker (low muscle mass, low handgrip strength, and slow gait speed), was proposed in the Aging Study of PyeongChang Rural Area cohort. The SPS showed better dose-response predictability of adverse health outcomes (mortality and institutionalization) compared to the pre-existing sarcopenia defi- nition, especially the revised definition from the EWGSOP. ${ }^{41)}$

\section{CONCLUSION}

Mostly living as a single household, Korean older adults had higher education levels and higher private income compared with that reported previously. In contrast to previous reports from the 2017 survey, we noted the increasing adoption of information technology in the older population. Moreover, economic status is improving in this population. We also observed trends in the older population of caring for their own health and having improved satisfaction with their general health. Healthcare providers and policymakers should reflect these current characteristics of older adults to pursue healthy aging and establish an age-friendly healthcare 
environment.

\section{ACKNOWLEDGMENTS}

\section{CONFLICT OF INTEREST}

The researchers claim no conflicts of interest.

\section{FUNDING}

None.

\section{AUTHOR CONTRIBUTIONS}

Conceptualization, JYB, IYJ; Data curation, JYB, HWJ, IYJ; Investigation, JYB, HWJ; Methodology, JYB, IYJ; Supervision, HWJ, EJL, IYJ; Writing-original draft, JYB, HWJ; Writing-review \& editing, JYB, HWJ, EJL, IYJ.

\section{REFERENCES}

1. Kim KW, Kim OS. Super aging in South Korea unstoppable but mitigatable: a sub-national scale population projection for best policy planning. Spatial Demography 2020;8:155-73.

2. Song JE, Ahn JA, Lee SK, Roh EH. Factors related to low birth rate among married women in Korea. PLoS One 2018;13: e0194597.

3. Kontis V, Bennett JE, Mathers CD, Li G, Foreman K, Ezzati M. Future life expectancy in 35 industrialised countries: projections with a Bayesian model ensemble. Lancet 2017;389:1323-35.

4. Jung HW, Kim KI. Multimorbidity in older adults. J Korean Geriatr Soc 2014;18:65-71.

5. Clegg A, Young J, Iliffe S, Rikkert MO, Rockwood K. Frailty in elderly people. Lancet 2013;381:752-62.

6. Jung HW, Lim JY. Geriatric medicine, an underrecognized solution of precision medicine for older adults in Korea. Ann Geriatr Med Res 2018;22:157-8.

7. Jang IY, Lee HY; Lee E; 50th Anniversary Committee of Korean Geriatrics Society. Geriatrics Fact Sheet in Korea 2018 from national statistics. Ann Geriatr Med Res 2019;23:50-3.

8. Ministry of Health and Welfare. 2020 National Survey of the Living Conditions and Welfare Needs of Older Koreans. Osong, Korea: Ministry of Health and Welfare; 2021.

9. Ministry of Health and Welfare. 2019 Long-term care status survey. Osong, Korea: Ministry of Health and Welfare; 2020.

10. Ga H. Long-term care system in Korea. Ann Geriatr Med Res 2020;24:181-6.

11. Statistics Korea. 2019 Population and Housing Census [Internet]. Daejong, Korea: Statistics Korea; 2020 [cited 2021 Jun 27]. Available from: http://kostat.go.kr/portal/eng/pressReleas- es $/ 1 /$ index.board bmode $=$ read $\& a S e q=386089$.

12. Statistics Korea. Life tables of Korea, 2019 [Internet]. Daejong, Korea: Statistics Korea; 2020 [cited 2021 Jun 27]. Available from: http://kostat.go.kr/portal/eng/pressReleases/8/6/index. board.

13. Korea Centers for Disease Control and Prevention. National Health and Nutrition Survey 2009-2019. Osong, Korea: Korea Centers for Disease Control and Prevention; 2019.

14. Korean Society of Hypertension. Hypertension Fact Sheet 2020. Seoul, Korea: Korean Society of Hypertension; 2020.

15. Korean Diabetes Association. Diabetes Fact Sheet 2020. Seoul, Korea: Korean Diabetes Association; 2020.

16. National Institute of Dementia. "Dementia today" [Internet]. Seoul, Korea: National Institute of Dementia; c2021 [cited 2021 Jun 27]. Available from: https://www.nid.or.kr/info/today_list. aspx.

17. Han SJ, Jung HW, Lee JH, Lim J, Moon SD, Yoon SW, et al. Clinical Frailty Scale, K-FRAIL questionnaire, and clinical outcomes in an acute hospitalist unit in Korea. Korean J Intern Med 2021; Jun 4;[Epub]. https://doi.org/10.3904/kjim.2020.677.

18. Jung HW, Baek JY, Jang IY, Guralnik JM, Rockwood K, Lee E, Kim DH. Short Physical Performance Battery as a crosswalk between frailty phenotype and deficit-accumulation frailty index. J Gerontol A Biol Sci Med Sci 2021;Mar 29; [Epub]. https://doi. org/10.1093/gerona/glab087.

19. Jung HW, Jang IY, Lee YS, Lee CK, Cho EI, Kang WY, et al. Prevalence of frailty and aging-related health conditions in older Koreans in rural communities: a cross-sectional analysis of the aging study of Pyeongchang rural area. J Korean Med Sci 2016;31:34552.

20. Jung HW, Kim S, Jang IY, Shin DW, Lee JE, Won CW. Screening value of timed up and go test for frailty and low physical performance in Korean older population: the Korean Frailty and Aging Cohort Study (KFACS). Ann Geriatr Med Res 2020;24:259-66.

21. Jung HW, Kim SW, Ahn S, Lim JY, Han JW, Kim TH, et al. Prevalence and outcomes of frailty in Korean elderly population: comparisons of a multidimensional frailty index with two phenotype models. PLoS One 2014;9:e87958.

22. Kim KJ, Shin J, Choi J, Won CW. Discrepancies in the prevalence of known frailty scales: Korean Frailty and Aging Cohort Study. Ann Geriatr Med Res 2018;22:137-44.

23. Ko RE, Moon SM, Kang D, Cho J, Chung CR, Lee Y, et al. Translation and validation of the Korean version of the clinical frailty scale in older patients. BMC Geriatr 2021;21:47.

24. Ko Y, Choi K. Prevalence of frailty and associated factors in Korean older women: the KLoSA study. J Women Aging 2017;29: $15-25$. 
25. Lee JE, Chun H, Kim YS, Jung HW, Jang IY, Cha HM, et al. Association between timed up and go test and subsequent functional dependency. J Korean Med Sci 2020;35:e25.

26. Lee Y, Chon D, Kim J, Ki S, Yun J. The predictive value of social frailty on adverse outcomes in older adults living in the community. J Am Med Dir Assoc 2020;21:1464-1469. e2.

27. Park H, Jang IY, Lee HY, Jung HW, Lee E, Kim DH. Screening value of social frailty and its association with physical frailty and disability in community-dwelling older Koreans: aging study of PyeongChang rural area. Int J Environ Res Public Health 2019; 16:2809.

28. Park MH, Ha JC, Shin IH, Kim HG, Lee SY, Cho JH, et al. Korean geriatric survey report 2008. Seoul, Korea: Ministry of Health \& Welfare; 2009.

29. Won CW, Lee Y, Lee S, Kim M. Development of Korean Frailty Index for Primary Care (KFI-PC) and its criterion validity. Ann Geriatr Med Res 2020;24:125-38.

30. Hwang HS, Kwon IS, Park BJ, Cho B, Yoon JL, Won CW. The validity and reliability of Korean frailty index. J Korean Geriatr Soc 2010;14:191-202.

31. Jung HW, Jang IY, Lee CK, Yu SS, Hwang JK, Jeon C, et al. Usual gait speed is associated with frailty status, institutionalization, and mortality in community-dwelling rural older adults: a longitudinal analysis of the Aging Study of Pyeongchang Rural Area. Clin Interv Aging 2018;13:1079-89.

32. Oh BT, Hwang YS, Lee JY, Park SK, Hong SW, Shu YS, et al. Factors related with hand grip strength in Korean elderly. Korean J Clin Geriatr 2017;18:22-9.

33. Cha S, Kim WS, Kim KW, Han JW, Jang HC, Lim S, et al. Sarcopenia is an independent risk factor for dysphagia in community-dwelling older adults. Dysphagia 2019;34:692-7.

34. Hong N, Siglinsky E, Krueger D, White R, Kim CO, Kim HC, et al. Defining an international cut-off of two-legged countermovement jump power for sarcopenia and dysmobility syndrome. Osteoporos Int 2021;32:483-93.

35. Jang IY, Jung HW, Lee CK, Yu SS, Lee YS, Lee E. Comparisons of predictive values of sarcopenia with different muscle mass indices in Korean rural older adults: a longitudinal analysis of the Aging Study of PyeongChang Rural Area. Clin Interv Aging 2018;13:91-9.

36. Kim KM, Lim S, Choi KM, Kim JH, Yu SH, Kim TN, et al. Sarcopenia in Korea: prevalence and clinical aspects. J Korean Geriatr Soc 2015;19:1-8.

37. Kim M, Won CW. Prevalence of sarcopenia in community-dwelling older adults using the definition of the European Working Group on Sarcopenia in Older People 2: findings from the Korean Frailty and Aging Cohort Study. Age Ageing 2019; 48:910-6.

38. Kim S, Kim M, Won CW. Validation of the Korean Version of the SARC-F questionnaire to assess sarcopenia: Korean Frailty and Aging Cohort Study. J Am Med Dir Assoc 2018;19:40-45. e1.

39. Lim S, Kim JH, Yoon JW, Kang SM, Choi SH, Park YJ, et al. Sarcopenic obesity: prevalence and association with metabolic syndrome in the Korean Longitudinal Study on Health and Aging (KLoSHA). Diabetes Care 2010;33:1652-4.

40. Kim S, Kim M, Lee Y, Kim B, Yoon TY, Won CW. Calf circumference as a simple screening marker for diagnosing sarcopenia in older Korean adults: the Korean Frailty and Aging Cohort Study (KFACS). J Korean Med Sci 2018;33:e151.

41. Jang IY, Lee E, Lee H, Park H, Kim S, Kim KI, et al. Characteristics of sarcopenia by European consensuses and a phenotype score. J Cachexia Sarcopenia Muscle 2020;11:497-504. 